\title{
Powder for Dental Solution Dosage Form
}

National Cancer Institute

\section{Source}

National Cancer Institute. Powder for Dental Solution Dosage Form. NCI Thesaurus. Code C149818.

Solid preparation consisting of one or more powders intended to be dissolved in the specified liquid to obtain a dental solution. 